\title{
An Analysis of the Revised "Learning Guideline" for Senior High School Citizenship Curriculum in Japan
}

\author{
Wei Liu, Min Liu, Yifan Ruan* \\ School of Marxism, China University of Geosciences, Wuhan, China \\ *Corresponding author
}

\begin{abstract}
In March 2018, in the global context of students' development of key competencies, the Ministry of Education, Culture, Sports, Science and Technology of Japan issued the Revised "Learning Guideline" for Senior High School, which has brought significant revision to the objectives, curriculum content, and teaching requirements in the senior high school citizenship curriculum. In terms of curriculum objectives, three "pillars"--namely "knowledge and skills", "thinking abilities, judgment and expression power", and "study ambition and human nature", of training high school students are emphasized. In terms of curriculum content, three subjects-The Public, Ethics, and Politics and Economy, are set up to constitute the new curriculum system of citizenship. In terms of teaching requirements, specific requirements are made for the "quality and ability" objectives of each subject to be achieved on the "three pillars". The newly revised senior high school "Learning Guideline" of citizenship course highlights the epochal character and value orientation of citizenship course, focuses on the convergence and operability of the objectives of citizenship course, and emphasizes the openness and flexibility of the content of citizenship courses, which has certain enlightening value.
\end{abstract}

Keywords: Japan, Learning Guideline, Senior high school, Civics

\section{INTRODUCTION}

"Learning Guideline" is a guiding document issued by the Ministry of Education, Culture, Sports, Science and Technology of Japan to guide the teaching of kindergarten, primary school, junior high school and senior high school curriculum, and is revised approximately every ten years. In the global context of developing students' key competencies, Japan carried out the latest round of curriculum reform in 2014. In September 2016, the Ministry of Education, Culture, Sports, Science and Technology of Japan released the document "Review and Summary of the Revision of the Next Learning Guideline" which comprehensively revised the "Learning Guideline", and issued the latest senior high school "Learning Guideline" in March 2018 with the intention to implement it among fresh students of senior high school enrolled in April 2022. The revised "Learning Guideline" focuses on the topics of "How do students learn?" and "What quality and ability should be trained among students?" while emphasizing the sociality of education and the implementation of "Subjectivity, Interaction, and Deep learning" in classroom teaching, which reflects the latest developments and changes of the educational ideas and theories in the Japanese primary and secondary education.

\section{THE BACKGROUND AND CAUSES OF THE REVISION OF THE SENIOR HIGH SCHOOL "LEARNING GUIDELINE" IN JAPAN}

According to the relevant documents of the Ministry of Education, Culture, Sports, Science and Technology of Japan, the revision of "Learning Guideline" has always adhered to the basis of social reality, national policies, laws and regulations and the students' learning conditions and educational needs. This revision of the "Learning Guideline" is the second curriculum reform in Japan after entering the new millennium. Compared with the previous reform, this curriculum reform copes with "a more complex and unpredictable future society", puts forward objectives on qualities and abilities, and provides reform plans on both teaching contents and methods according to a large-scale survey of students' learning conditions.

In the first place, the revision adapts to the rapid changes of Japanese society. The Japanese Central Education Review Council points out that the 21st century is an epoch of "Knowledge-based Society". In 2008, the curriculum reform of basic education in Japan has given priority to the focus on "Knowledge-based Society". In recent years, the rapid development of globalization, informationization and digitalization, especially the artificial intelligence technology has brought opportunities and challenges to human society including education. 
Questions such as "Will the rapid development of artificial intelligence have an impact on human occupation?" and "Does the content taught in schools today apply to the epoch of rapid development of society and economy?" keep emerging. Global issues such as environmental pollution and resource shortages have also impelled people to rethink where school education should go and what education schools should provide to enable students to better manage their lives. Based on this condition, the newly revised "Learning Guideline" believes that the basic goal of curriculum reform is to train the necessary ability of students in the rapidly changing social, namely the "viability", which is generally consistent with the "Key Competencies" proposed by the OECD.

Secondly, the revision meets the needs of the newly revised laws and regulations. Japan's Basic Act on Education revised in 2006 clearly points out that the basic goal of education is: to foster an attitude to acquire wide-ranging knowledge and culture; to seek the truth, cultivate a rich sensibility and sense of morality, while developing a healthy body; to develop the abilities of individuals while respecting their value; to train their creativity; to foster a spirit of autonomy and independence; to foster an attitude to value labor while emphasizing the connections with career and practical life; to form the value of active participation in building the society and contributing to its development, in the public spirit as well as the value of respect for other countries and the desire to contribute to world peace and the development of the international community. Japan's School Education Law also pointed out that "In order to enable students to form lifelong learning ability, we should pay attention to the acquisition of basic knowledge and skills, develop the ability of 'thinking abilities, judgment and expression power' of flexibly applying knowledge and skills to solve practical problems, and foster the attitude of independent learning". This revision of the "Learning Guideline" is to meet the requirements of the Basic Education Law, School Education Law and other laws, emphasizing the further development of the qualities and abilities of young people to create the future, and emphasizing "Society-oriented Curriculum", having the ability for sharing and cooperating with society, emphasizing the balanced development of knowledge and skills, and training in thinking abilities, judgment and expression power. While further improving the quality of understanding of knowledge and developing reliable subject skills, attention should be paid to the participation in social experiencing activities.

Thirdly, the revision improves the existing situation of students' learning. In 2018, the Japanese Senate passed an amendment to the Civil Law that reduced the age of adults from 20 to 18, and it will be implemented on April 1, 2022 (implemented simultaneously with the revised Senior High School Learning Guideline). Therefore, it becomes more important to train the qualities and abilities required by the society on each student in senior high school. Research and Discussion on "The Status and Issues of the Senior High School Curriculum in 2015 and the Status Quo in the Future" released by the Ministry of Education, Culture,
Sports, Science and Technology of Japan show that, on the one hand, compared with their international peers, the current senior high school students in Japan lack enthusiasm and willingness to actively participate in social activities. Very few students neither believe that they can use their own force to change the worldor nor fully understand the basic concepts of ethics, politics and economy with an absence of the ability to use information and various methods to study realistic topics. On the other hand, students' enthusiasm in studying the political and economic structure as well as their significance is very high. They believe that the importance of political and economic learning is next only to Japanese and foreign languages. Therefore, it is increasingly urgent to highlight the importance of citizenship curriculum in senior high school and continuously improve and enrich objectives and contents of the citizenship curriculum in order to adapt to social changes.

\section{THE BASIC PRINCIPLES OF THE REVISION OF THE SENIOR HIGH SCHOOL "LEARNING GUIDELINE" IN JAPAN}

The important basis in the revision of the "Learning Guideline" of senior high school in Japan is the report "Improvements and Necessary Programs on Learning Guideline for Kindergartens, Elementary Schools, Middle Schools, Senior High Schools, and Special Support Schools" issued by the Central Education Commission on December 21, 2016. The report clearly pointed out that the revision of the "Learning Guideline" of primary school, junior high school and senior high school mainly focused on the following issues (as shown in Figure 1):

Focusing on the above issues, the report identifies the basic guiding ideology for the revision as follows: based on the "Basic Act on Education" and "School Education Law", the practical experience of previous school education should be given full play, and the quality and ability of students to create future society should be further effectively trained. Therefore, schools should strengthen the cooperation with the society to train the qualities and abilities students need to acquire, paying attention to the balance between the learning of knowledge and skills, and the training of "thinking abilities, judgment and expression power". Improve further the quality of students' understanding of knowledge, train solid learning ability, improve moral education, attach importance to experience activities, enrich physical education and health guidance, and cultivate students' rich soul and a healthy body. To be more specific,

Firstly, the training of "quality and ability" is the basic aim of the curriculum teaching. The report replied by the Central Education Review Council pointed out that in a rapidly changing and highly competitive society, it is necessary to be able to think independently about "how to create the future" and "how to make society and life better", and have the ability to create a better society and a 
better life by giving full play to one's potential. This kind of ability is not brand-new, but a reorientation of "Viability" in Japanese school education goal for a long time. Therefore, according to the Generic Capabilities that are generally valued in the international community, the revised objectives in terms of "quality and ability" are based on the following three "pillars": (1)The learning of "knowledge and skills" required for life and work; (2)The training of "thinking abilities, judgment and expression power" in response to unknown situations; (3)The development of "study ambition and human nature" in applying the knowledge and skills learned in future life and society. And the curriculum objectives and contents of each subject should be revised based on the three "pillars". Secondly, "Subjectivity, Interaction, and Deep learning" is the basic teaching and learning methods. At present, most of the curriculum contents of senior high school in Japan are oriented to college entrance examination, emphasizing the impartation of knowledge with an absence of the training of quality and ability related to social life. In order to improve the quality of senior high school learning, to make students understand profoundly the close relationship between what they have learned with life and society, to make them have the quality and ability required for future society, and to make them have the ability of lifelong learning, the newly revised "Learning Guideline" requires the full implementation of the teaching mode of "Subjectivity, Interaction, and Deep learning" Among them. "Subjective learning" emphasizes that students have an independent learning attitude and interest, which can reflect their own learning activities in time, and apply the lessons learned to the next learning; "Interactive learning" emphasizes acquiring knowledge through cooperation with others and interaction with the outside world, and constantly expands and deepens one's own way of thinking; "Deep learning" emphasizes the activation of thinking based on the characteristics of various disciplines in inquiry learning, the integration and deep understanding of knowledge, the discernment of the value of information, the discovery and solution of problems, and the innovation and creation based on self-thinking.

Thirdly, strengthening curriculum management is the key of pedagogical reform. In order to train the ability of using language and information as the basis of learning, the ability of finding and solving problems, and the quality and ability of coping with various contemporary issues, each school should integrate the objectives and contents of each subject, strengthen the connection between the learning of each subject, and strive to carry out "Subjectivity, Interaction, and Deep learning" on the basis of integrating the subjects, contents and teaching time of each unit. At the same time, all schools should strengthen curriculum management, properly grasp the actual situation of students, schools and regions, reasonably arrange teaching content and hours, ensure the necessary human and material resources, carry out reform according to the implementation of education curriculum, improve the quality of education activities, and strive to maximize the learning results.

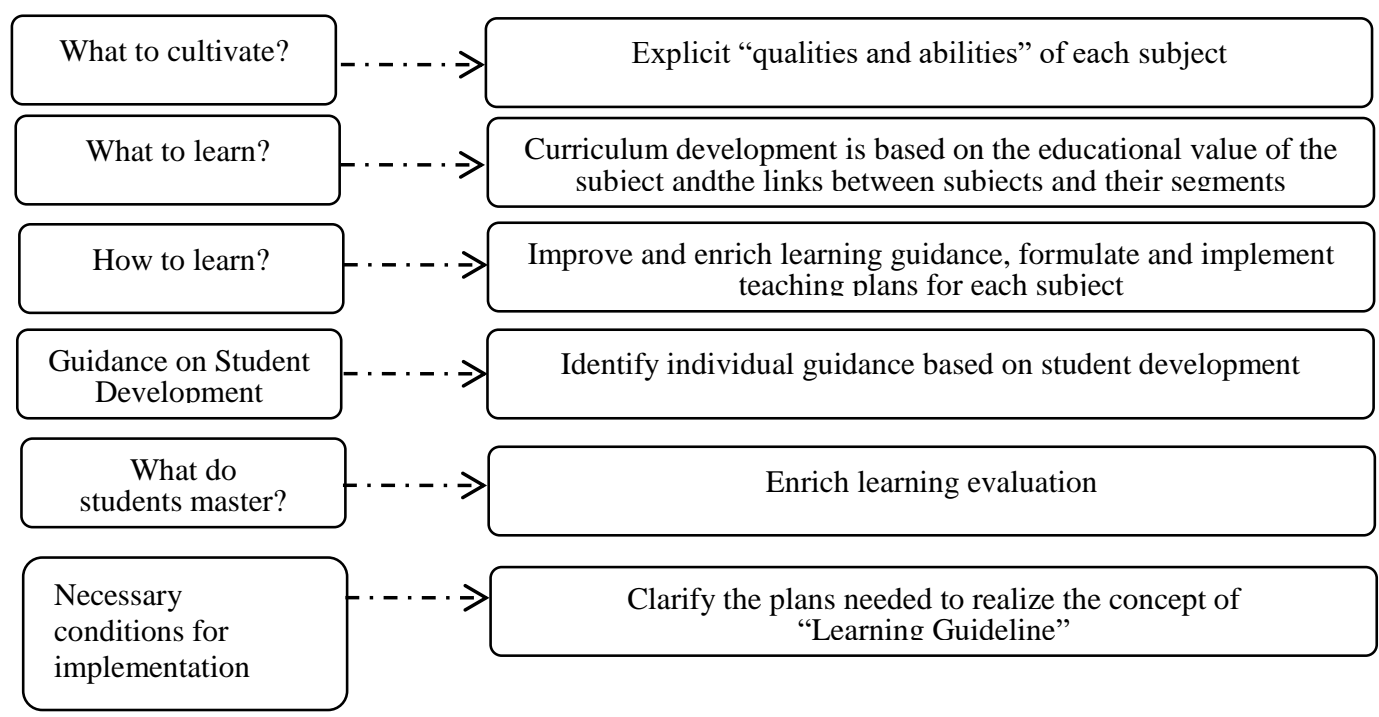

Figure 1 Revision Scheme of Japanese "Learning Guideline"

\section{THE MAJOR CONTENTS IN THE REVISION OF "LEARNING GUIDELINE" FOR SENIOR HIGH SCHOOL CITIZENSHIP CURRICULUM IN JAPAN}

Based on the background, causes and basic principles of the aforementioned revision of the "Learning Guideline" for the senior high school, the Ministry of Education, Culture, Sports, Science and Technology of Japan revised the curriculum objectives, content structure, and teaching requirements of the senior high school citizenship curriculum. The objectives and contents of the newly revised senior high school citizenship curriculum are adjusted in accordance with the three "pillars" to make the 
curriculum objectives clearer, the curriculum content richer, and the teaching requirements for each subject more specific.

\subsection{Curriculum Objectives for the Course of Citizenship in Senior High School}

While retaining some of the objectives of the previous version of the "Learning Guideline", the newly revised curriculum objectives adhere to the principle of gradual and progressive improvement of the primary-junior high school - senior high school curriculum education objectives. Compared with the current "Learning Guideline", there are great differences in the curriculum objectives of the newly revised "Learning Guideline". The comparison of the objectives of citizenship curriculum before and after revision is shown in the Table 1.

From the above table, we can see that the revised curriculum objectives for the course of Citizenship in senior high school not only continue to emphasize on the broad perspective and train the qualities of citizens required for the "formers" of "a peaceful and democratic country and society.", but also focus on the globalization background and international vision to apply a social perspective to train the quality and ability that contemporary citizens must possess from a social point of view through exploring and solving the problem of contemporary activities.
Specifically, the objectives of the newly revised curriculum explain specific qualities and abilities that senior high school students should be trained based on the revised policy of the "Senior High School Learning Guideline" released by the "Response Report of the Central Education Council", the training objectives of the citizenship curriculum for elementary and junior high schools and the characteristics in the development of senior high school students, the development of the "three pillars" - "knowledge and skills" "thinking, judgment, and expression power" and "study ambition and human nature". Among the newly revised curriculum objectives, the first focus is the objective of knowledge and skills, that is, to understand the concepts and theories of choice and judgment and learn basic knowledge of ethics, politics and economy through the activities of exploring and solving modern projects, to properly and effectively use the social perspective and thinking mode, and grasp the skills to properly and effectively collect necessary information from various materials according to the problems to be solved. The second focus is the objective on abilities, including the ability to investigate social events from different aspects and angles, the ability to make objective judgments in face of social problems, the ability to think about themselves and others' opinions, and reach consensus. The third focus is the objective of emotional attitudes, that is, to foster students' attitudes to actively explore and solve contemporary issues, as well as the consciousness of citizens shouldering the civic rights to love the country and contribute to the realization of a better and sustainable society.

Table 1 The comparison of the objectives of citizenship curriculum before and after revision

Curriculum objectives of the newly revised "Learning Guideline"
Based on a broad vision, from the social perspective and way of thinking,
through the activities of exploring and solving contemporary issues, foster
among students the following qualities and abilities of citizens to become the
promising formers living in a globalized international society, a peaceful and
democratic country and society:
1) While understanding the concepts and theories of choice and
judgment, and contemporary topics such as ethics, politics and economy,
attempt to acquire the skills to properly and effectively investigate and
summarize information from various materials.
2) For contemporary topics, students should be trained to investigate
from different aspects and angles based on facts, to make fair judgments and
solve problems, and to discuss and conceive when participating in society and
reaching consensus.
3 ) With the goal of building a better society, students should be trained
to solve contemporary problem; their awareness should be cultivated to act
with the proper living methods of human beings through thinking from
different aspects and angles with deep understanding. As citizens living in
public space and shouldering the civic rights of the country, students'
understanding of the importance of loving their country, seeking its peace and
prosperity, respecting each other's sovereignty, and cooperating with people of
all countries should be deepened.

Curriculum objectives of the current "Learning Guideline"

Based on a broad vision, train students to study the modern society; and while deepening their understanding, cultivate students' awareness of the way of life as human beings, and the quality of citizens as promising formers living in a peaceful and democratic country and society.
In the newly revised curriculum objectives, the "social perspective and way of thinking" refer to the "perspective and ideas" that are conceived to solve social issues by exploring the meaning, characteristics and interrelationships of social phenomena, which help to train students' ability of deep thinking and judgment, and 
constitute the key factor of the overall quality and ability training. "The activity of exploring and solving modern issues" indicates that students set learning issues by collecting materials and conducting social investigation in combination with the course contents, and understand the characteristics and significance of social phenomena while thinking, judging and expressing the issues to improve their concerns for the society. This learning and inquiry process is conducive to the actual realization of "Subjectivity, Interaction, and Deep learning", and can use "knowledge and skills" to think, judge and express in the process of inquiry, so that students can be effectively trained in the quality and ability demanded by the three "pillars".

\subsection{Curriculum Contents and Structure for the Course of Citizenship in Senior High School}

In terms of curriculum structure, three subjects, namely "Modern Society", "Ethics", and "Politics and Economy", constitute the current curriculum system of senior high school citizenship curriculum in Japan. The newly revised curriculum system for the course of Citizenship, however, is comprised of "The Public", "Ethics", and "Politics and Economy" "The public" is not only a new and compulsory subject, but also the core subject in the curriculum of Citizenship in senior high school. It should be completed in the year of enrollment and the next two years. All students are required to finish "The Public" subject before they are allowed to study "Ethics" and "Politics and Economy". In terms of curriculum content, this revision is based on the concept of "Socially-oriented Curriculum", that is, a good school education should be oriented to society and the world with a broader perspective, and create a better society through the implementation of the school curriculum and social goals in common talent training. Therefore, the major contents of the new senior high school citizenship curriculum are closely related to the current social, public, ethical, and political and economic issues in Japan. The contents of revised Citizenship curriculum are shown in the Table 2:

Table 2 The contents of revised Citizenship curriculum

\begin{tabular}{|c|c|c|}
\hline Subjects & Major Category & Sub-category \\
\hline \multirow{8}{*}{$\begin{array}{l}\text { The } \\
\text { Public }\end{array}$} & \multirow{3}{*}{ Public gate } & Create our public space \\
\hline & & The way of human existence in public space \\
\hline & & Basic principles of public space \\
\hline & \multirow{2}{*}{$\begin{array}{l}\text { As an independent force, we should } \\
\text { participate in building a better society. }\end{array}$} & Mainly legal matters \\
\hline & & $\frac{\text { Mainly political matters }}{\text { Mainly economic matters }}$ \\
\hline & \multirow{3}{*}{$\begin{array}{l}\text { We are major force in building a } \\
\text { sustainable society. }\end{array}$} & Actively participate in district production \\
\hline & & $\begin{array}{l}\text { Actively participate in building a better country and a } \\
\text { better society }\end{array}$ \\
\hline & & Actively participate in the international community \\
\hline \multirow{4}{*}{ ethic } & \multirow[b]{2}{*}{$\begin{array}{l}\text { About contemporary life and the way of } \\
\text { human life }\end{array}$} & Human awareness of the way of existence \\
\hline & & $\begin{array}{l}\text { The awareness of Japanese people living in the } \\
\text { international community }\end{array}$ \\
\hline & \multirow[t]{2}{*}{ Contemporary Issues and Morality } & $\begin{array}{l}\text { Topics and ethics related to natural science and } \\
\text { technology }\end{array}$ \\
\hline & & Issues and ethics related to social culture \\
\hline \multirow{3}{*}{$\begin{array}{l}\text { Politics } \\
\text { and } \\
\text { economy }\end{array}$} & \multirow{2}{*}{$\begin{array}{l}\text { Politics and economy in contemporary } \\
\text { Japan }\end{array}$} & Political and economic issues in contemporary Japan \\
\hline & & $\begin{array}{l}\text { Research on political and economic issues in Japan } \\
\text { Contemporary international nolitics and economy }\end{array}$ \\
\hline & $\begin{array}{l}\text { Various issues of the international } \\
\text { community }\end{array}$ & $\begin{array}{l}\text { Research on various issues of the international } \\
\text { community }\end{array}$ \\
\hline
\end{tabular}

\subsection{Teaching Requirements for the Course of Citizenship in Senior High School}

Training students to have the necessary "quality and ability" required as a citizen of contemporary society is one of the characteristics of this revision of the "Learning Guideline". In order to better achieve the objective of cultivating the "quality and ability" of citizens through the study of Citizenship curriculum, the "Learning Guideline" explains "knowledge and skills", "thinking abilities, judgment and expression power", and "study ambition and human nature" in each subject in detail, and integrates the training of the quality and ability of citizens into the specific content of the course, providing right direction and specific requirements for teachers' teaching. The corresponding quality and ability of the subject of The Public, Ethics, and Politics and Economy are shown in the Table 3. 
Table 3 The corresponding quality and ability of the subject

\begin{tabular}{|c|c|c|c|}
\hline Subjects & Knowledge and skills & $\begin{array}{l}\text { Thinking abilities, judgment and } \\
\text { expression power }\end{array}$ & $\begin{array}{c}\begin{array}{c}\text { Study ambition and } \\
\text { human nature }\end{array} \\
\end{array}$ \\
\hline The Public & $\begin{array}{c}\text { Grasp and explore } \\
\text { contemporary issues; , master } \\
\text { the skills as an ethical subject } \\
\text { to properly and effectively } \\
\text { investigate and summarize the } \\
\text { necessary information from } \\
\text { various materials }\end{array}$ & $\begin{array}{l}\text { From the perspective of public } \\
\text { space, possess the ability to make } \\
\text { fair judgment, participate in } \\
\text { society and form consensus by } \\
\text { applying the way of } \\
\text { choice-making and } \\
\text { judgment-making, and the basic } \\
\text { principles of public space }\end{array}$ & $\begin{array}{l}\text { Investigate and explore } \\
\text { contemporary issues from } \\
\text { various aspects and } \\
\text { perspectives, and understand } \\
\text { the way of human existence; } \\
\text { be willing to contribute to } \\
\text { building a better society }\end{array}$ \\
\hline Ethics & $\begin{array}{l}\text { Grasp all kinds of ethical } \\
\text { problems in the contemporary } \\
\text { world, and master the skills of } \\
\text { investigating and summarizing } \\
\text { information related to people's } \\
\text { way of life from various } \\
\text { materials }\end{array}$ & $\begin{array}{l}\text { From the perspective of current } \\
\text { ethnical issues, master relevant } \\
\text { concepts and theories, and to gain } \\
\text { the ability to communicate with } \\
\text { others and live together }\end{array}$ & $\begin{array}{l}\text { Study the phenomena and } \\
\text { topics related to human life } \\
\text { style, and be willing to } \\
\text { create a better life with } \\
\text { others }\end{array}$ \\
\hline $\begin{array}{l}\text { Politics and } \\
\text { Economy }\end{array}$ & $\begin{array}{c}\text { Explore contemporary } \\
\text { socio-political and economic } \\
\text { issues, and acquire the skills to } \\
\text { investigate and summarize } \\
\text { information related to the way } \\
\text { of social existence from } \\
\text { various materials }\end{array}$ & $\begin{array}{l}\text { From the perspective of current } \\
\text { social politics and economy, } \\
\text { understand the theory of choice } \\
\text { and judgment and the related } \\
\text { phenomena of politics and } \\
\text { economy, and gain the ability to } \\
\text { build consensus and participate in } \\
\text { society }\end{array}$ & $\begin{array}{l}\text { Explore contemporary } \\
\text { political and economic } \\
\text { issues, narrow the distance } \\
\text { between students themselves } \\
\text { and political economy, and } \\
\text { take the initiative to build a } \\
\text { democratic country and } \\
\text { society }\end{array}$ \\
\hline
\end{tabular}

\section{THE BASIC CHARACTERISTICS OF THE REVISED "LEARNING GUIDELINE" FOR SENIOR HIGH SCHOOL CITIZENSHIP CURRICULUM IN JAPAN}

\subsection{Highlighting the Epochal Characteristic and Value Orientation of Citizenship Course}

According to the new changes and requirements of the social development in Japan, the newly revised "Learning Guideline" of senior high school set up the "Public" as a compulsory subject of citizenship curriculum, which fits into the global context of students' development of key competencies. "The Interpretation on Learning Guideline of Senior High School", issued by the Ministry of Education, Culture, Sports, Science and Technology of Japan in July 2018, pointed out that the subject of "Public" should promote the cultivation of students' awareness of social engagement, the establishment of public spirit and the cultivation of patriotic feelings. It also emphasizes the deepening of the consciousness of citizen's political participation of with political rights and improving their quality and ability to participate in social politics. All this demonstrates that the newly-ordered Citizenship curriculum of senior high school in Japan is given a strong attribute in terms of political service. The word "public" is the opposite of "private" and "individual" in Japanese, which focuses on the meaning of government and official regime organizations in contrary to individual citizens and civil society, and carries a very prominent ideological sense. Although the "Learning Guideline" did not define the word "public" in detail, however, as the most authoritative interpretation of senior high school citizenship teaching, it fully reflects the national will of Japan in an attempt to spread its values among young students with an obvious value orientation.

\subsection{Emphasizing the Cohesion and Operability in the Objectives of the Citizenship Course}

Based on the three "pillars" of "knowledge and skills", "thinking abilities, judgment and expression power", and "study ambition and human nature", the newly revised "Learning Guideline" for senior high school Citizenship curriculum explicits what kind of "quality and ability" should be trained among senior high school students in the Citizenship course. This revision emphasizes the overall design of the curriculum teaching objectives of primary school, junior high school and senior high school, and makes major adjustments in the form and connotation, striving to strengthen the connection and progression of different grades and subjects, and using integrated thinking to deal with the relationship between the overall objectives of citizenship curriculum and the objectives of various subjects. At the same time, the newly revised "Learning Guideline" follows the rules for the formation of cognition and morals of senior high school students and the characteristics of different subjects, and clarifies the quality and ability that each subject should train based on the three "pillars", which makes the training of quality and ability clearer, more specific, more operable, and performs a more obvious guiding role for teachers to organize teaching and for students to learn. 


\subsection{Focusing on the Openness and Flexibility of the Contents of Citizenship Course}

The response report of the Central Education Review Committee proposed that Japanese schools and society should form a consensus on "Creating a better society through better school education" and construct a dual model of school society in practice. In order to enable students to effectively integrate into the real situation related to the society, get the real sense of the purpose and significance of learning of each subject, and improve their concern for the society. The newly revised senior high school "Learning Guideline" proposed the concept of "Socially-oriented Curriculum", aiming to improve the relevance between the curriculum content and the society and life. On the one hand, it emphasizes that schools use local resources and strengthen collaboration with the regions, so as to build a two-dimensional pattern of school and society to educate students together. On the other hand, schools can conduct "Local Education", actively organize students to participate in social experience and survey activities, and optimize the two-way interaction between students and local society, which is conducive to promote students' ability to adapt to complex society and the capacity innovation.

\section{CONCLUSION}

To sum up, the revised "Learning Guideline" is an adjustment based on both the revision experience of previous editions of "Learning Guideline" and the development of social reality in Japan. The revised "Learning Guideline" emphasizes the new issues and challenges faced by the Japanese society during the transformation period, emphasizing the epochal and socialized role of curriculum objectives, and focuses on the training of students' ability of self-adjustment, social adaptation and innovation. The design of its curriculum content highlights practical operation and teacher-student interaction to improve the teaching quality, and focuses on training students" "quality and ability". In teaching practice, importance is attached to the cooperation between the school and the society, utilizing the social educational resources to guide the students to learn actively so as to gradually adapt to and integrate into the social environment.

\section{References}

[1] ZHANG Yue, LI Shuwen, Miziyisi hazuo, Review of the New Junior High School Science Course of Study in Japan, J Primary \& Secondary Schooling Abroad. 2019(06):75-80+39.

[2] Information on http://www.mext.go.jp/component/b_menu/shingi/toush in/_icsFiles/afieldfile/2016/09/09/1377021_1_1_11_1. pdf,2016-8-26.

[3] Infomation on

http://www.mext.go.jp/component/a_menu/education/m icro_detail/_icsFiles/afieldfile/2019/03/28/1407073_0 4_1_1.pdf

[4] Information on http://www.mext.go.jp/component/b_menu/shingi/giji/_ _icsFiles/afieldfile/2019/06/25/1418185_12.pdf

[5] Liu Jihe, Interpretation of the new curriculum standard of junior high school science in Japan, J Global Education. 2009, 38(3):64-68.

[6] Information on

http://www.japaneselawtranslation.go.jp/law/detail/?id= $2442 \& v m=04 \& r e=02$

[7] Information on https://www.mext.go.jp/b_menu/shingi/chukyo/chukyo 0/toushin/1380731.htm

[8] Information on https://www.mext.go.jp/content/1421692_4.pdf

[9] Information on https://www.mext.go.jp/a_menu/shotou/new-cs/138466 2.htm

[10] Information on https://www.mext.go.jp/a_menu/shotou/new-cs/140707 4.htm 